\title{
"Raça", ressentimento e racismo: transformações na África do Sul*
}

\author{
Thomas Blaser** \\ Brigitte Bagnol \\ Zethu Matebeni \\ Anne Simon \\ Sandra Manuel
}

\section{Resumo}

A partir de uma perspectiva qualitativa, este artigo analisa a forma como as pessoas "negras" na África do Sul esforçam-se por superar e ressignificar as marcas de uma história de repressão e de marginalização "raciais". Seguiremos a trajetória de Mpho, uma mulher "negra" com o objetivo de refletir como "raça" e gênero articulados envolvem situações de negociação, coerção, ressentimento e recusa. Estudaremos como certos indivíduos reorganizaram suas redes de sociabilidade no pós-apartheid, com foco no "campo de possibilidades" disponível para diferentes grupos "raciais".

Palavras-chave: Reconciliação, Raça, Racismo, Gênero, Joanesburgo, África do Sul.

\footnotetext{
* Recebido para publicação em julho de 2010, aceito em outubro de 2010.

** Thomas Blaser, pós-doutorado, Humanities Graduate Centre, (thblaser@gmail.com); Brigitte Bagnol, conferencista visitante senior no Departamento de Antropologia (bagnolbrigitte@gmail.com); Zethu Matebeni, Doutoranda, WISER (zethu.matebeni@gmail.com); Anne Simon, conferencista em tradução, Departamento de Estudos de tradução e de interpretação (anne.m.simon@gmail.com) - todos na Universidade de Witwatersrand, Johannesburgo, África do Sul; Sandra Manuel, Lecturer, Departamento de Anthropologia, Universidade Eduardo Mondlane, Maputo, Moçambique, (sandra.manuel@uem.mz).
}

cadernos pagu (35), julho-dezembro de 2010:111-137. 
"Raça", ressentimento e racismo: transformações na África do Sul

"Race", Resentment and Racism:

Transformation in South Africa

\begin{abstract}
From a qualitative perspective, this paper analyses how "black" people in South Africa strive to overcome and ressignify the marks of a history of repression and "racial" marginalization. We will follow the trajectory of Mpho, a "black" woman, with the objective to reflect on how the intersection of "race" and gender involve situations of negotiation, cohersion, ressentment and refusal. We will study how some individuals reorganize their network of sociability in post-apartheid South Africa with a focus on the "field of possibilities" available for different "racial" groups.
\end{abstract}

Key Words: Reconciliation, Race, Racism, Gender, Johannesburg, South Africa. 
Thomas Blaser et alii

\section{Introdução}

Após a Segunda Guerra Mundial, o estado sul-africano resistiu à corrente mundial que concedia mais autonomia $e$ até independência aos povos colonizados. Em 1948, os sul-africanos "brancos"1 elegeram um governo do Partido Nacional simpático à causa nazi. Nas décadas que se seguiram, o apartheid, um sistema de leis e políticas para garantir a supremacia branca e a segregação "racial", consolidou-se. O sistema foi abolido em 1994 nas primeiras eleições verdadeiramente democráticas.

No entanto, seria um engano atribuir o apartheid unicamente aos indivíduos que lideraram o partido vitorioso, sem levar em consideração os precursores $e$ as relações sociais que possibilitaram a execução de políticas de cunho "racial". Desde que os europeus "brancos" se instalaram no século XVI na ponta meridional do continente africano, tomou forma um processo de formação, confrontação e exclusão racial. Esse movimento - que levou os intrusos coloniais a ocupar o território e subjugar seus habitantes - não foi linear, tampouco unívoco. Ao contrário, os registros das lutas prolongadas por terras e poder mostram que o significado de "raça" passou por inúmeras mudanças $e$ transformações. Esse processo continua a desdobrar-se, mesmo depois do fim do apartheid, forjando novos sentidos à ideia de "raça" e (re)significando antigas formas de exclusão.

1 O uso dos termos "branco" e "negro" não significa uma aceitação dessas classificações, antes, indica sua persistência no cotidiano e na legislação sulafricanas. São mencionados entre aspas para indicar categoriais socialmente criadas organizando relações desiguais de poder entre pessoas e grupos sociais. 
"Raça", ressentimento e racismo: transformações na África do Sul

\section{O aparecimento da ordem "racial" sul-africana: uma leitura}

Debates históricos sobre o papel da fronteira ${ }^{2}$ nos séculos XVIII e XIX, entre colonos (afrikaners e inglês) e africano (xhosa $e$ san), indicam a complexidade dos diversos processos de formação "racial" na região. Historiadores do século XIX atribuíram o racismo e a supremacia coloniais unicamente a uma atitude que evoluiu entre os fazendeiros "brancos" que atuavam na fronteira.

Pesquisas posteriores, entretanto, sustentaram que as diferenciações "raciais" foram forjadas na sociedade colonial na sua globalidade e não apenas na fronteira, configurando-se como uma herança européia $e$, concomitantemente, respondendo às exigências de situações em constante mudança nos territórios (Legassick, 1980:68). Alternaram-se o comércio e a guerra, a cooperação e o conflito $e$, se bem o racismo desempenhou um papel no processo, não foi o único fator (Legassick, 1980:65). Colonos afrikaners, comerciantes ingleses, grupos xhosa, mestiços ("coloured") comerciantes, caçadores san e soldados ingleses todos competiam para os mesmos recursos na fronteira. As pessoas faziam alianças independentemente dos grupos linguísticos ou de "cor" de acordo com seu interesse e capacidade. Segundo Hermann Giliomee (1979:457), na fronteira, o significado das identidades social e "racial" estava marcado pela fluidez. Embora o autor tenha detectado uma rigidez "racial" crescente durante o conflito entre colonos "brancos", africanos e outros grupos de composição "racial" e social diversas que viviam na fronteira, a estratificação com base na raça não dependia apenas da percepção "racial" e "étnica" européia. A insistência afrikaner em criar a sua própria nação era essencialmente para manter o seu estatuto social. Assim, a classe social era um elemento fundamental na criação de relações de poder. Segundo o autor, existiam grupos "com posições variáveis na escala social", mas

2 Conceito analítico usado na historiografia do racismo na África do Sul para se referir à zona de contacto entre os diferentes grupos (ver Giliomee, 1979; Legassick, 1980; Penn, 2005). 
nesta escala o movimento entre diferentes grupos "raciais" era reduzido. De um lado as pessoas eram diferenciadas em função da sua "cor", mas também de acordo com o seu estatuto. Por exemplo, um bom caçador "negro" negociando com os colonos "brancos" podia ter um alto estatuto e recursos provenientes da venda dos animais e da pele.

A difusão do conflito, pautado por dimensões "raciais" e de classe, dificultou as negociações e a busca por soluções (Giliomee, 1979:461). A fronteira como formação social e geográfica é simultaneamente um momento de resistência/contestação e de conquista/rigidez. As transformações nas formas de produção e de exploração criam relações e percepções diferentes entre as pessoas $e$ os grupos com características físicas e origens distintas.

Após a conquista militar, os colonos agricultores e o estado sul-africano, através da introdução da agricultura capitalista, deslocaram de forma sistemática a população africana (Beinart $e$ Delius, 1986:111). A subjugação e a incorporação na economia capitalista andavam de mãos dadas, de forma que os grupos africanos independentes foram despojados das suas terras $e$ obrigados a servir de mão-de-obra (Keegan 1986:247). Perdendo acesso à sua sobrevivência tornaram-se a mercê dos colonos, fixando-se desse modo as relações entre os grupos europeus $e$ africanos.

Com a emergência de regimes particulares de trabalho, os grupos "raciais" e "étnicos" se encontraram em atividades distintas. No centro urbano emergente de Joanesburgo, em finais do século XIX, por exemplo, organizações de taxistas foram constituídas por judeus europeus, evitando tenazmente a colaboração com outros grupos "étnicos" e "raças" envolvidos no mesmo negócio (Van Onselen, 1982).

A segregação territorial e política foi sendo enraizada nos anos 1920 e 1930. A exclusão de pessoas "negras" implicou igualmente no apoio aos fazendeiros, a proteção aos trabalhadores urbanos e aos pobres, todos eles "brancos" (Giliomee, 1979). Contudo, as fronteiras territoriais entre o "negro" 
"Raça", ressentimento e racismo: transformações na África do Sul

e o "branco" não eram rígidas como se tornaram na década de 50. Os africanos deslocaram-se para as cidades para procurar seu sustento. Ao longo do século $\mathrm{XX}$, o fortalecimento desse movimento constituiu um fator importante para acabar com $\mathrm{O}$ apartheid.

A análise das confrontações na fronteira levou Giliomee (1979) e Penn (2005) a distinguir a fronteira "aberta" e "fechada" para se referir às diferentes fases da experiência dos encontros entre sujeitos nos territórios de colonização. Ambos mostram como as diferentes fases da fronteira tornaram possíveis diferentes formas de arranjos e de relações. A fronteira "aberta" define situações em que as relações não são ainda estabelecidas e são flexíveis, contestadas e em formação. Em oposição, a fronteira torna-se "fechada" quando, na região, as relações de produção $e$ social estão estruturadas e definidas por uma legislação que garante os interesses dos colonos.

\section{$O$ apartheid e suas sequelas}

Com a implementação da Lei de Registro da População, de 1950, que separou a população em quatro grupos "raciais" nomeadamente europeus, asiáticos, "mestiços" ("coloured") $e$ "nativos" -, o governo lançou os alicerces de um sistema com base na divisão "racial". Essa lei facilitou a edificação de uma sociedade segregada, regida por normas diferentes e múltiplas, atribuindo direitos e obrigações igualmente diferenciados com base na raça. A partir de 1952, segundo Posel (1991:116), "o estado tinha o direito, em termos jurídicos, de exercer vastos poderes sobre o movimento, a residência e o emprego dos africanos". As leis de controle de movimento (pass laws) foram alargadas para abranger qualquer indivíduo africano com mais de 16 anos. Além disso, a criação de juntas de reassentamento, que tinham o poder de remover os africanos das zonas onde fossem indesejáveis, e a implementação da Lei das Áreas Reservadas (Group Areas Act), de 1950, que delimitou cuidadosamente as 
áreas permitidas para cada grupo "racial", levaram à proteção adicional dos espaços unicamente para "brancos" e ao controle mais intenso dos movimentos das populações. Conforme Steyn (2001b:88), "as pessoas eram socializadas para o que era considerado como o espaço social adequado para elas, sendo os recursos articulados em conformidade" com essa lógica.

Somente os "brancos" podiam ocupar os centros das cidades (por exemplo, Hillbrow e Yoeville), assim como alguns bairros suburbanos. Os indianos e "mestiços" ("coloured") foram alocados em espaços específicos na periferia das cidades, enquanto os africanos ("negros") ocuparam locais ainda mais afastados, denominados townships (favelas ou bairros populares), por exemplo, Soweto. Muitos africanos, em busca de emprego nas cidades, foram alojados em residências (hostels) de sexo único dentro dos townships (Guillaume, 2001), sendo obrigados a abandonar suas famílias. As separações familiares ocorreram igualmente entre os trabalhadores agrícolas nas zonas rurais.

Após as primeiras eleições democráticas de 1994, tem-se a sensação de que a África do Sul, repentinamente, se tornou uma sociedade multicultural e mista com pessoas de uma miríade de origens, dotadas de direitos iguais, liberdade de associação e de movimento. Aqueles que foram ensinados, através das estruturas políticas, sociais e econômicas, a viver separados já estavam, "de boa ou má vontade, bem-sucedidos ou não, envolvidos em um dos mais profundos ajustamentos psicológicos coletivos do mundo contemporâneo" (Steyn, 2001a:xxi). A abolição do regime do apartheid possibilitou acesso a espaços, independente de sua origem "racial", e a contestação de fronteiras consagradas pelos conceitos reificados das identidades raciais.

Apesar da abolição antecipada, em 1985, da Imorality Act e da Mixed Marriage Act - leis de 1927 e 1949, respectivamente, que criminalizavam a relação sexual inter-racial $e$ os casamentos mistos -, "a freqüência de contato e cooperação inter-raciais tem se modificado lentamente" (Amatoeng et alii, 2004:444). Como demonstra Moutinho (2004), essas leis são expressões da forma 
"Raça", ressentimento e racismo: transformações na África do Sul

como a sexualidade foi gerida no período do apartheid, através da "raça". A evocação de pânicos morais acerca da ameaça sexual dos homens "negros" contra as mulheres afrikaners, aludida pelos ideólogos do regime de separação racial $e$, de fato, não confirmada estatisticamente, conspirou para o restabelecimento das hierarquias de gênero, poder e "raça" por parte dos homens afrikaners (Moutinho, 2004 e Hyslop, 1995:58-50). Seguindo essa direção, o estudo de Amatoeng et alii destacou que, ao contrário da convicção de que quanto mais reduzido o grupo, maior a probabilidade de que seus integrantes encontrem parceiros fora de seu grupo, raramente as pessoas "brancas" ou indianas procuram parceiros fora de seus grupos. Efetivamente, as relações dos sulafricanos baseiam-se principalmente em constrangimentos sociais (Amatoeng et alii, 2004:455). Os autores mostram que a taxa de exogamia é mais elevada entre grupos lingüísticos, sobretudo entre as pessoas "negras" - "alguns dos grupos lingüísticos estão mais ligados do que os grupos raciais" (Id.ib.:456).

Essa breve descrição indica como as relações "raciais" se desenvolveram na África do Sul, mas as diferenças regionais, particularmente entre as áreas rurais e urbanas, são consideráveis. Nas zonas rurais, a segregação "racial" tem sobrevivido com força, a despeito da chegada da democracia.

Ao longo das décadas, os planificadores da urbanização, agindo em consonância com as elites urbanas ("brancas"), projetaram as cidades conforme suas necessidades e geografias, trabalhando na manutenção de fronteiras e na contenção dos contatos. Por toda a África do Sul, nos centros "brancos" das cidades - com os seus edifícios e centros comerciais modernos, seus bairros suburbanos opulentos, com casas de grande dimensão com jardins - as pessoas viviam "uma existência extremamente etnocêntrica, em grande medida inconscientes da vida dos outros" (Steyn, 2001b:90). Para assegurar a segregação, na periferia da cidade "branca", os arquitetos do apartheid colocaram townships com seus dormitórios (hostels) e um grande 
número de pequenas casas (matchboxes ${ }^{3}$ ), tão homogêneas que se parecem com cadeias. Esse modo de urbanização remete às idéias desenvolvidas por Foucault em Vigiar e Punir (1975) - uma estrutura que cria e sustenta uma hierarquia de poder. A disciplina faz-se cumprir através da imposição de formas estritas de desumanização, num espaço fechado e separado da cidade, com normas mínimas de urbanismo e de vida social, visando a manutenção de possibilidades suficientes, apenas, para reproduzir a força de trabalho.

Guillaume (2001:37) analisa como a paisagem foi projetada de modo a excluir as pessoas de seu estatuto urbano (e humano), servindo como "ferramenta para a dominação e a exclusão da população africana". O espaço privado limita-se à casa. A maior parte do pequeno quintal está ocupada por casas precárias (zozo), nas quais vivem agregados unidos ou não por relações familiares com os ocupantes da casa principal. Essa privação encontrou seu ponto culminante nas residências descritas em A Bed Called Home [Uma Cama Chamada Casa], de Ramphele (1993), em que a cama constituía o elemento estruturante da vida e da identidade dos trabalhadores. Milhares de homens partilhavam poucos banheiros e chuveiros, às vezes sem portas. A precariedade e o alto custo do transporte, a falta de espaços públicos e de serviços $e$ a privação generalizada se justapunham à imagem de pobreza do township, criando formas variadas de violência, incluindo a sexual. Nesses espaços, que não foram concebidos para o desenvolvimento da expressão $e$ da vida individual, desenvolveram-se as identidades sociais e o que atualmente se denomina "a cultura do township". 4

Em meados dos anos 1970, foi registrado o primeiro abrandamento da Lei das Áreas Reservadas (Group Área Act),

${ }^{3}$ Os Africanos chamavam de matchbox (caixa de fósforos) casas de um quarto construídas para eles pelo regime do apartheid.

${ }^{4}$ A cultura do township está caracterizada por um modo de vida, um estilo musical, uma maneira de se vestir e de encarar a sexualidade $e$ as incertezas do cotidiano. 
"Raça", ressentimento e racismo: transformações na África do Sul

levando ao assentamento de famílias "mestiças" $e$ indianas na cidade "branca" (Morris, 1999). Em 1991, após a abolição da Lei, um grande número de africanos dos bairros populares circundantes mudou-se para a cidade. Essa transformação na ocupação do centro da cidade levou os habitantes "brancos" a abandonarem edifícios empresariais e institucionais nas áreas do centro comercial de Joanesburgo, de Braamfontein e de Hillbrow, perto do centro. Em 1993, a maioria dos moradores dos prédios em Hillbrow era africana (62\%), com uma minoria de "mestiços" $(22 \%)$ e "brancos" (16\%), modificando, assim, o ambiente de lazer e a composição sócio-cultural com o aparecimento de instalações mistas (Morris, 1999). Segundo Mbembe (2004:391), esse afluxo manifestou uma tentativa de adquirir cidadania urbana e ascender na "escada" social. No final dos anos 1990, Yeoville - bairro perto do centro da cidade - converteu-se em uma zona "inter-racial" de lazer e vida noturna.

Atualmente, Joanesburgo é uma cidade jovem - $42 \%$ da população têm menos de 24 anos - contudo, um número elevado de jovens tem um acesso precário ao ensino, à saúde $e$ ao emprego. A vida juvenil está enquadrada num contexto de uma das distribuições de rendimento mais desiguais do mundo, agravada por desigualdades "raciais". Portanto, a cultura juvenil urbana evoluiu como resultado de um processo permanente de descontinuidade e de tensões - pobreza, desemprego, violência estrutural, instabilidade socioeconômica e cultural. A falta de alternativas formais condena os jovens a todo tipo de estratégias informais de subsistência. Os laços familiares nem sempre conseguem garantir uma vida segura, ou um ponto de referência cultural e social a um/a jovem em busca de sua própria identidade, momento em que se negociam valores $e$ comportamentos divergentes. Em Joanesburgo, a maior parte dos agregados familiares (66\%) é chefiada por uma única pessoa, indicando a ausência, para a maioria dos jovens, de apoio por parte de ambos os pais.

Perante as desigualdades, ainda fortemente marcadas por 
questões "raciais" - embora o desnível entre as "pessoas "negras" pobres e ricas esteja se alargando -, a reconciliação e a coexistência pacífica entre os "brancos" e "negros" foram elevadas ao estatuto de doutrina. Dumisa Ntsebeza, ex-diretor da unidade de investigação da Comissão da Verdade e da Reconciliação, sustenta que seu trabalho não conseguiu promover a reconciliação entre perpetrador e vítima, assim como entre os beneficiários majoritariamente "brancos" e as vítimas majoritariamente "negras" (Bell e Ntsebeza, 2003:349). Mínimas reparações financeiras foram concedidas pelo Estado àqueles que foram considerados vítimas, enquanto os culpados de crimes hediondos receberam anistia. Além disso, para muitos, a atividade empresarial "branca", que prosperou durante o apartheid, nunca teve, de fato, que "pagar a conta". Nas notas finais, Ntsebeza considera que

criou-se a impressão de que o processo da Comissão da Verdade e Reconciliação foi efetivamente leve para com os transgressores e desrespeitoso e cruel para com as vítimas e sobreviventes (Bell e Ntsebeza, 2003:348).

A compreensão de Ntsebeza sobre as ações da Comissão de Verdade e Reconciliação vem ganhando a cena pública nos últimos anos. O governo do ex-Presidente Nelson Mandela fez um esforço consciente no sentido da conciliação $e$ do não questionamento do princípio de reconciliação e de co-existência pacífica.

O entendimento de que a convivência de "negros" $e$ "brancos" está baseada na injustiça é recorrente na narrativa de Mpho, uma jovem "negra" cuja trajetória acompanharemos a seguir. Para ela, enquanto os "negros" perdoaram, os "brancos" se beneficiaram do apartheid e continuam a fazê-lo sem arrependimento. Apesar de essa visão ter como base um passado que separa os "negros" e os "brancos", as mudanças nas condições sociais e econômicas criam novas identidades que estão 
"Raça", ressentimento e racismo: transformações na África do Sul

incorporadas ou emaranhadas, como sugere Sarah Nuttall (2004), nas maneiras de ser européias ou "brancas".

\section{Como se vive "raça": a voz de uma mulher "negra"}

Tendo estabelecido os antecedentes da construção histórica da "raça" na África do Sul, passamos a examinar como evoluíram as percepções de "raça" e de identidade no período pósapartheid. A narrativa de Mpho - que não se afirma como uma representante dos "negros" sul-africanos - oferece novas percepções sobre a forma como a "raça" é vivida em um contexto específico. Mpho exprime sua percepção da injustiça.

Mpho é o pseudônimo atribuído a uma mulher "negra" que tinha cerca de vinte anos em 2007 e que cresceu num township no sudoeste de Joanesburgo. Mpho ficou órfã de pai muito jovem. Ela foi criada por sua mãe, professora primária e com sua irmã que é estudante universitária. Ela é aluna de cinema numa escola de Joanesburgo. Sobre o lugar onde cresceu, Mpho diz:

Sou de C... uma pequena vila, muito racista, muito Afrikaner... Penso que uma das coisas que deveras se destaca acerca de C. [é que é]... muito racista, muito atrasada, uma vila muito primitiva.

Mpho explica o que "raça" significa para ela:

Raça é... é uma certa denominação de, de... não sei, o que é raça? Raça define quem você é, define onde você nasceu, como foi educada, a cor da sua pele. Provavelmente determina os seus valores, os seus traços de personalidade. É problemático em muitos aspectos porque pode definir a maneira com a qual você é tratada e como é recebida por outra pessoa. Sabe o que eu quero dizer! Para algumas pessoas é uma maldição ou um peso, para outras pessoas é uma vantagem. 
Para Mpho, "raça" é um conceito definindo vários marcadores de diferença que incluem implicitamente a classe social e consequentemente também as redes de sociabilidade e as relações de poder. Mpho vê na ideia de raça um elemento determinante ao ponto de poder-se tornar uma "maldição". A sua trajetória de vida nos mostra como ela está por vários meios conseguindo desfazer essa "maldição".

Ante o racismo enfrentado no seu lugar de nascimento, Mpho faz referência ao sentido de comunidade entre as pessoas "negras", que as ajudou a superar a privação, encontrar conforto e diversão:

Você sabe como é que as pessoas negras têm uma natureza ligada à comunidade e ao estar-se juntos... divertindo-se e rindo-se o tempo todo ou, se calhar não rindo, mas simplesmente divertindo-se... dando uma mão, ou seja, a pior situação converter-se-ia nos melhores momentos, quero dizer que havia momentos nos quais a energia elétrica se apagava, sabes, então toda a zona ficava na completa escuridão, e nós as crianças gritávamos "yii! vamos para a rua!".

Numa situação de privação, crianças e adultos encontram formas de solidariedade $e$ de socialização particularmente calorosas. Essas formas de lidar com a privação social contribuiu para forjar o que significava ser "negro" em vez de "branco". Atualmente, essa experiência partilhada de opressão serve concomitantemente para distinguir os sul-africanos "negros" de outros africanos "negros" ou pessoas de várias "cores" e origens que resistiram ao apartheid dos que não passaram por essa experiência. Nesse sentido, a identidade "negra" está ligada ao lugar e à história. As diferenças de classe se intersectavam com uma identidade "negra" comum: pequenos privilégios materiais por exemplo, uma merenda farta - afetavam a amizade entre as crianças. 
"Raça", ressentimento e racismo: transformações na África do Sul

(...) Se a minha mãe me desse para o almoço na escola um pacote de doces, um pacote de batatinhas, um sumo e uma maçã, as crianças na escola, digamos se eu abrisse minha lancheira na hora do almoço, as crianças na escola não brincariam comigo, simplesmente porque elas não dispunham da mesma coisa. Portanto, eu passaria por períodos de não ter amigos, simplesmente porque as crianças pensariam que eu era superior aos outros.

Outro indicador da diferença de classe é a proficiência na língua inglesa, que foi, e continua sendo, um elemento de distinção entre crianças "negras" na escola. Se o bom manejo da língua inglesa aproximava Mpho das crianças "brancas", essa habilidade era motivo de afastamento de crianças "negras", que achavam que ela já não fazia parte do seu grupo.

Outra coisa era que o meu inglês era de fato bastante bom, muito mais avançado do que muitas das outras crianças negras que haviam entrado na escola. Portanto, mais uma vez por causa disso eu fiquei condenada ao ostracismo $e$ estava alienada de todas as outras crianças negras, por acharem-me superior, porque eu podia falar melhor inglês, eu passava muito bem. Então eu não contava com muitos amigos.

A referência de Mpho ao conceito de "passar" remete ao fato dela ser uma boa aluna e "passar de ano", mas também pode se referir ao fato de se enquadrar num ambiente "branco". Às vezes, o "passar" (passing) refere-se no contexto sul-africano a pessoas "negras" com uma tonalidade da pele clara "passar por" ou ter a possibilidade de "serem tomadas" por pessoas "brancas". Falar bem inglês significa, para alguns, abandonar sua identidade "negra" para inserir-se no meio dos "brancos" e pertencer à classe média ou alta. Dependendo do contexto, a intersecção de marcadores sociais de diferença produz formas de inclusão ou de exclusão, formas de dominação ou de subjugação diferentes. Nos exemplos da Mpho, o lanche e o falar bem inglês tornam-se 
marcadores de exclusão entre os "negros" $e$ inclusão entre os "brancos". Assim, os contextos nos quais intersectam os marcadores da diferenças são fundamentais em produzir novos sentidos e novas hierarquias.

$\mathrm{O}$ trecho a seguir indica o ressentimento de Mpho ante a visão dos professores sobre a história do apartheid, que conflitava com sua própria experiência, a de sua família e a da comunidade, provocando seu distanciamento dos colegas "brancos". O que ela aprendeu na escola sobre a história do país não correspondia à situação política nas vésperas das primeiras eleições democráticas em 1994, à sua experiência e à da sua comunidade no que se refere às relações entre as pessoas "negras" e "brancas".

$\mathrm{Na}$ quarta ou quinta classe você começa a aprender geografia, história ou qualquer coisa, portanto, é nessa altura que a situação ou o contexto social entra em jogo, sabes...

Refletindo retrospectivamente, a escola que eu freqüentei era, efetivamente, bastante racista. Esta história na escola primária era muito branqueada, muito de lavagem do cérebro. Fazia com que as pessoas brancas estivessem bem e, como uma pessoa negra, ou uma criança negra, eu penso que podia ver que havia problemas com as pessoas brancas, mas, na época, parecia que "ai não, as pessoas brancas não são tão más. Havia problemas por causa dos seus antepassados... isto e aquilo". Portanto, foi nessa época que me dei conta da minha distância das pessoas brancas, mas... eu ainda tinha um ou dois amigos brancos.

Na escola primária, a melhor amiga de Mpho era uma menina irlandesa, em cuja casa ela costumava pernoitar. Contudo, sua amiga nunca dormiu na casa dela no township, segundo Mpho, provavelmente devido às manipulações da mãe de sua amiga, assegurando-se de que sua filha não pernoitasse em um township "negro". Nas suas palavras: 
"Raça", ressentimento e racismo: transformações na África do Sul

Nunca se tratava de vir para a minha casa. Simplesmente não nos demos a essa maçada. Acho que era porque éramos crianças, mas é provável que houvesse igualmente alguma manipulação por parte dos seus pais, sabes? A preocupação e coisas assim. Ah... Tenho a certeza de que discutimos isso, mas por alguma razão simplesmente nunca se concretizou... Portanto, foi assim a escola primária.

Mpho lembra que, afora o castigo corporal, os confrontos "raciais" na sua escola majoritariamente "branca" constituíram a pior experiência do seu tempo estudantil.

Havia muito racismo, mas eu pessoalmente não o vivi a partir dos colegas de escola com os quais estava associada, sabes? Contava-se que um menino branco deu sova a um menino preto porque este teria dito isto e aquilo; um rapaz preto foi bater num menino branco, por causa de quaisquer motivos, sabes? Penso que havia muitos problemas mesmo entre as outras culturas, como as dos indianos e dos mestiços ("coloured"), por causa de termos depreciativos como "kaffir", . Pois a gente indiana nos chamaria de "kaffir" e nós a eles de "coolie"6, termo igualmente depreciativo. Os mestiços ("coloured") chamar-nos-iam de "kaffir" e nós a eles de "macaco da floresta", sabes?!

Mpho lembra que, apesar das eleições democráticas de 1994, as práticas da sua escola, anteriormente "branca", foram mudando muito lentamente.

Ao longo de todos os sete anos do meu ensino primário, continuamos a cantar o Hino Nacional dos Afrikaners.

5 "Kaffir" é um termo pejorativo para pessoa "negra" e se assemelha ao norte americano "nigger".

6 "Coolie" é um termo pejorativo para pessoa de descendência indiana, que historicamente significava trabalhador braçal, especialmente utilizado para designar chineses e indianos.

7 Termo racista associando africanos a macacos. 
Imagina!!! Continuamos a cantar o Hino Nacional dos Afrikaners, o qual era como.... hum?! Pois essas coisas deviam ter sido abolidas por completo, mas por algum motivo esquisito ainda estavam presentes. Ya! Uma escola muito pequena, muito pitoresca, muito primitiva, muito atrasada, de caráter afrikaans em grande medida. $\mathrm{O}$ afrikaans era [ainda] a segunda língua que tínhamos que aprender.

Alguns anos mais tarde, Mpho tinha amigos "negros" na escola secundária e tornou-se mais consciente da "raça" e de como o racismo tinha afetado e ainda afetava a sua vida.

Depois, na escola secundária, eu encontrei-me mais ou menos, contava com amigos negros. Tudo mais ou menos se encaixou, ou seja, nem tudo, mas eu aprendi mais acerca de mim mesma e aprendi acerca da pessoa negra que sou. Foi nessa altura que me tornei mais consciente da situação social à minha volta e foi nessa altura que comecei a sentir a discriminação, o racismo e os preconceitos. Tal como quando eu tinha dezesseis anos, tentei obter o meu primeiro emprego, mas não o consegui por ser negra. Eu tentava ser empregada de mesa e o meu patrão me dizia: "Não, não posso permitir que você trabalhe como empregada de mesa, pois os meus clientes são na sua maioria brancos e não querem receber comida de uma pessoa negra", sabes... coisas dessas... Entrar num centro comercial e uma pessoa branca simplesmente empurrava o carrinho contra você, simplesmente por não gostar de ti por seres negra. Coisas dessas... E ya, esse era o tipo de situação social em C.

Num restaurante de C., de recepcionista, ela passou a trabalhar como garçonete, mas ao cometer uma falha com um dos clientes, que se queixou à direção, a patroa explicou que ela não poderia continuar nessa função. 
"Raça", ressentimento e racismo: transformações na África do Sul

Quando esse homem queixou-se, eu consegui entender porque havia reclamado, pois ele é um dos meus clientes assíduos e é muito afrikaans e muito conservador ou qualquer coisa assim e é um dos clientes que dizem que não querem ser atendidos por pretos por causa de qualquer motivo que inventaram na cabeça. Quem é que eles pensam que está na cozinha? Sabe... Quem você pensa é que faz a comida? Entende o que quero dizer?

Nesse contexto de racismo, Mpho e a sua família se mudam para a zona da cidade antigamente reservada somente aos "brancos".

Depois mudamos para o centro da cidade, para uma zona muito branca. E é aí quando eu perdi completamente contacto com... Não ser negra! Mas com muitos traços negros em mim. Isso é quando minha mãe, minha irmã e eu nos tornamos o triângulo que somos agora porque éramos literalmente a única família negra do bairro assim tínhamos que contar umas com as outras. Sabes, a minha mãe tem tentado melhorar as coisas para nós. Numa pequena vila como $\mathrm{C}$., melhorar a vida tem a ver com a acumulação de capital e a mudança para o centro da cidade, a posse de carros, basicamente a obtenção de um certo prestígio. O prestígio significa que você muda para o centro da cidade e demonstra a todos os outros que você tem os meios para fazer isto e aquilo, tem os recursos para viver ali e para conduzir aquilo, esse tipo de coisas. Era simplesmente algo que a minha mãe vinha sempre a querer fazer. Outro motivo era a segurança. O township não era a zona mais segura para habitar, levando em consideração o fato de nós sermos três pessoas de sexo feminino que viviam numa casa e a nossa casa tinha uma cerca, por onde as pessoas podiam saltar sem dificuldade. Por isso saímos.

Os aspectos de gênero $e$ a dificuldade das três mulheres se sentirem seguras aparecem como uma motivação para mudar-se para um bairro "branco" contribuindo também para uma 
mudança em termos de status para Mpho, sua irmã e sua mãe. Por viver entre pessoas "brancas", elas assumiam características que não eram consideradas como próprias de uma identidade "negra". Assim, em adição à classe social e ao falar inglês, a residência é um marcador de identidade social e de diferença que transformou a vivência e a identidade da Mpho. Registra-se, assim, uma certa maleabilidade dos marcadores de diferenças $e$ nota-se como manipulando-os Mpho e sua família afastam-se da identidade "negra" e do que ela chamou de "maldição". A transformação de marcadores permite a construção de identidades novas. De uma noção de raça e de discriminação rígida somente definida pela "cor", a história da Mpho mostra a possibilidade de transformação e de contestação das desigualdades no pósapartheid.

Porém, Mpho não se relaciona bem com os seus vizinhos "brancos", ressaltando sua hipocrisia ao se mostrarem amigáveis, quando, na verdade, eles nutrem certo desdém em relação a ela e à sua família.

Se estão na companhia de pessoas ou com outros familiares brancos, eles não acenam para nós. Caso estejam sozinhos então vão acenar... Tipo "não, não, não, nós não conhecemos nenhuns pretos"... Portanto, eu penso... não sei, detesto isso, eu penso que é tão hipócrita, tão superficial. Se pretende acenar, acene, caso não, deixe! Portanto, regra geral, eu mais ou menos me limito a não acenar de qualquer das maneiras - e a minha mãe está numa de "você! - diz bom dia", mas não, não vou cumprimentar essa gente. Eu tenho que saudá-las quando me apetece saudar. Eu simplesmente deixo-os assim.

$\mathrm{Na}$ universidade, Mpho confrontou a história sobre o apartheid com sua experiência pessoal e sente ressentimento em relação à injustiça que ela viveu e que ainda existe na sociedade. Ela expressa seu desconforto com o silêncio que o assunto ainda 
"Raça", ressentimento e racismo: transformações na África do Sul

reveste. Ela sofre da ausência de conclusão, de solução, expressando como o aspecto da reparação está ainda pendente.

Eu cursei História - penso que é uma das coisas que formou o meu esquema mental em termos de raça. Estávamos a aprender acerca da história sul-africana; foi o único foro no qual efetivamente tivemos a chance de debater os nossos problemas e a nossa história em pormenor. Discutíamos acerca de como isto tudo começou e quem é que de fato foi o primeiro em África e como é que os negros foram tratados e como é que as pessoas negras participaram nas guerras civis e é esta a sua recompensa, as Leis de Controlo de Movimento e isso tudo e... é aí onde você percebe a ampla gama daquilo que está a acontecer $e$ você consegue visualizá-lo na sua vida, assim como no lugar onde você vive. Mas depois que você sai dessa esfera da sala de aulas então fica esquecido. Tipo, você apenas partilha isso com as pessoas com as quais você estuda história ou com as pessoas com as quais você tem debates. Mas uma vez saído da sala de aulas, isso espalha-se com o vento, simplesmente desaparece por completo, pois se olha como se o outro não existisse e toda a gente age como se... sem contestar, continuamos a conformar-nos e ninguém está discutindo com qualquer outra pessoa, pois não há nada do gênero - somos uma nação arco-íris alegre! e disparates desses!, sabes?.

Mpho expressa o seu mal-estar, a sua raiva: "isso fica esquecido... espalha-se com o vento, simplesmente desaparece por completo ...e toda a gente age como se... sem contestar, continuamos a conformar-nos e ninguém está discutindo". Mpho acredita que o conceito de nação arco-íris, unindo "negro" $e$ "branco", é demasiadamente idealístico e não reflete a forma como as pessoas se relacionam umas com as outras atualmente. Ela considera que existem "assuntos pendentes" nas relações entre os "negros" e os "brancos" e mostra isso lembrando como as relações desiguais de poder estão incorporadas. Ilustrando esse 
aspecto, ela descreve como a interiorização da inferioridade aciona uma mudança do corpo de sua mãe na interação com "brancos":

[Quando minha mãe entra em contacto com os brancos] mesmo o seu corpo muda e os seus ombros, sabes? Não sei, eu penso que é algo que está intrinsecamente dentro dela, simplesmente de ser respeitosa e humilde, porque ela é branca... A minha mãe tem um físico suntuoso, ela anda de modo vaidoso, mas logo que fale com alguém de cor branca, ela simplesmente torna-se pequena, os ombros caem... quando entra em contacto com eles [os brancos]. E de uma certa forma isso ilustra a fato que tem sempre assuntos, muitos assuntos políticos pendentes, que estão sempre fervendo, que não foram resolvidos... Eu posso me dar conto porque estudei e por causa da minha cabeça, porque sou muito critica e analítica e eu leio muito de tudo $e$ por causa do que eu vivi... Eles nasceram numa época diferente, eles são passivos em relação a isso... É uma dessas coisas. Vê-se isso cada dia. Só tem que abrir os olhos e ver. Honestamente é uma coisa que acontece todos os dias na cidade onde vivo. (...) Penso que há sempre racismo em Joanesburgo, mas não penso que seja tão mal como em C. Porque não é um sítio diluído... cada coisa que está aí é como está... Sabes, não tem tais coisas como relações inter-raciais... e raramente vê-se um negro andar na rua com uma branca ou vice-versa. Sabes o que eu quero dizer... Em Joanesburgo tem mais integração em termos de cultura, em termos de língua, de hábitos $e$ sexualidade. É um lugar onde tudo acontece.

Quando Mpho foi para Joanesburgo cursar cinema, ela descobriu uma cidade que ela caracteriza como "diluída", onde os códigos e comportamentos não são tão rígidos como na sua cidade natal. Essa diluição dos códigos e a possibilidade de desenvolver novas relações remetem à situação da fronteira "aberta", onde simultaneamente ocorrem resistência/contestação e 
"Raça", ressentimento e racismo: transformações na África do Sul

conquista/rigidez. O "tudo é possível" de Mpho pode referir-se à construção de novas relações, a transformação das hierarquias, $e$ produção de novos marcadores, que não implicam obrigatoriamente na integração no molde social europeu. Por exemplo, para Mpho, algumas possibilidades estão fechadas como a relação sexual inter-"racial". Ela argumenta:

Eu penso que jamais namoraria com alguém de outra cor ou raça que não a minha, porque por muito que sou capaz de travar amizades com pessoas de outras raças $e$ conseguimos comunicar a qualquer nível e estarmos numa boa ou sei lá, não penso que numa relação em que as coisas ficam tão interligadas e tão emaranhadas, que se pode conectar a todos os níveis com alguém de outra raça. $\mathrm{Eu}$ penso simplesmente que é algo que é muito difícil passar. Se namorasse com um branco podíamos nos enganar no início e "não importa que sou branco e sou negra" e tudo isso... mas o assunto da cor poderia aparecer a qualquer momento sabes.

- "Sua mãe não gosta de mim porque sou negra".

- "Não querida, não é isso. Ela somente não entende o teu povo"

- "Meu povo? Então agora é meu povo? O que aconteceu com o "nada de cor"?

Sabes o que quero dizer. Acredito que é uma das coisas que constituiriam uma barreira constante entre nós dois. Mas, alguns conseguiram! Pessoalmente, para mim, não penso que alguém de uma outra cor possa entender a mim $e$ a minha cultura até o ponto de estar juntos e ser feliz. Eu sinto que sou uma pessoa muito culturalmente tradicional. Acredito nos antepassados. Faço os rituais. Não posso ter um namorado indiano que arrepia-se a vista do sangue porque estamos a matar o boi - é isso que fazemos em casa - é a nossa tradição... Acredito que cada negro tem uma responsabilidade perante a sua herança ancestral... isso é muito poderoso. 
Para Mpho, o que separa as pessoas "negras" e "brancas" é tão profundo que não tem remédio ou solução. Sequer pode ser resolvido em uma relação íntima. Ela vê na componente religiosa algo que estabelece uma barreira intransponível. Da mesma forma ela acredita que no cotidiano o assunto da raça iria surgir inevitavelmente.

Nos últimos tempos, no ambiente específico do universo do cinema, ela se confronta com discriminação de gênero. Nesse exemplo, as relações de gênero tomam precedência sobre a "raça". Um outro marcador da diferença emerge com maior força definindo as hierarquias de poder contra as quais insurge-se em busca de alternativas.

No início do ano tínhamos que fazer uma filmagem com outros estudantes para um filme (...) este moço, que é um realizador de cinema apaixonado, me dizia "é tão estúpido que as mulheres não são autorizadas no set $e$ o único trabalho que lhe deixam fazer é a continuidade $e$ a maquilagem. E sabes acredito que as mulheres podem fazer a câmera". Assim, depois disso comecei a gostar de estar no set $e$ fazer o trabalho manual. No nosso grupo estávamos decidindo as atividades e assumíamos responsabilidades. Eu disse que queria ser a camera woman. E um dos moços com quem eu estava trabalhando começa assim: "Estas mesmo segura?" e eu: "Sim estou segura, eu quero ser camera-man eu posso fazer câmera, sei o que fazer". E aí começamos. O moço que montou a luz estava confuso. Levou três horas e eu estou aquela camera-woman paciente. Espero tranquilamente. Fico sentada. E fazemos a primeira tomada e pedem para fazer a coisa mais difícil que existe em câmera: um zoom e uma panorâmica para baixo ao mesmo tempo. Não é algo que alguém consegue acertar da primeira vez. Fiz a primeira tomada e estava um pouco tremido. E eu: "desculpa é culpa minha". Faço a segunda tomada e "não, não, não, não está bem. Tenta de novo." Ok. Faço a terceira tomada. "desculpa gente podemos mudar de câmera. Penso que você não é suficientemente 
"Raça", ressentimento e racismo: transformações na África do Sul

boa para isso." E escolhem um moço aí. Acabei fazendo som. E o moço atrapalhou-se tanto quanto eu. Mas como era uma mulher não tinha palavra. Ao mesmo tempo eu pensava "Ok se eu me levanto e protesto ou qualquer coisa" eles vão dizer "Estas sendo emotiva, é esse o motivo pelo qual as mulheres não são aceitas no set." Assim parei $e$ pensei "ok querem que faça som vou fazer som." A partir deste momento comecei a ser pro-mulher no set. Eu não trabalho com homens na minha equipe. Quero uma equipe de mulheres comigo. Quero me afirmar como camerawoman, como uma pessoa técnica no set. Porque penso que é uma merda que as mulheres sejam tão marginalizadas quando se trata de produzir bons trabalhos. Assim esse foi um outro momento importante de discriminação que eu sofri.

No contexto específico do set de filmagem, extremamente machista, Mpho descreve um episódio em que as relações de gênero determinam o acesso a certas atividades de prestígio, como ao estatuto de camera-woman. Mpho quer adquirir esse estatuto e se confronta com seus colegas homens, adotando uma estratégia de exclusão dos homens da sua equipe técnica. Nesse ambiente, Mpho se confronta a novas formas de relações de poder não mais baseadas na classe ou na "cor", mas baseadas no sexo $e$ numa cultura machista com a qual ela deve lidar e vencer.

\section{Conclusão}

Ao longo de séculos, na África do Sul emergiu um regime "racial" específico, no qual a "raça" foi conectada à classe de maneira estrita e complexa. Durante muito tempo, o conceito de "raça" foi operado de modo fluido. Entretanto, quando o apartheid firmou suas bases legais e estritas, as categorias "raciais" oficialmente prescritas dividiram a sociedade de modo inequívoco.

No pós-apartheid, as pessoas "negras" e "brancas" vivem juntas numa sociedade democrática, na qual todos têm direitos e deveres iguais apesar da sua "raça". Entretanto, o significado da 
"reconciliação" $e$ as habilidades necessárias para alimentar o convívio entre grupos distintos mostram-se em disputa.

A narrativa de Mpho evidencia como sentimentos de injustiças (imersos em iniludível ressentimento) em relação às discriminações, ao racismo e à violência vividos no passado e no presente afetam sua coabitação com pessoas "brancas". Ainda que existam pontos de emaranhamento, o legado das discriminações e a (re)atualização de hierarquias e modos distintos de ser e agir assumem uma importância capital, fazendo com que o convívio esteja repleto de dificuldades e desafios.

\section{Referências bibliográficas}

AmoAteng, Acheampong Yaw; Heaton, Tim B. e JaCOBSON, Cardell K. Inter-Racial Marriages in South Africa. Journal of Comparative Family Studies (35), 2004, pp.443-458.

BeINART, William e Delius, Peter. Introduction. In: BeInART, W.; Delius, P. e TRAPIDO, Stanley. (orgs.) Putting a Plough into the Ground. Accumulation and Dispossession in Rural South Africa, 1850-1930. Johannesburg, Ravan, 1986, pp.1-55.

BeLl, Terry e NTSEBEZA, Dumisa Buhle. Unfinished Business. South Africa, Apartheid, and the Truth. London/New York, Verso, 2003.

FoucAult, Michel. Discipline and Punish. New York, Pantheon, 1977.

GILIOMEE, Hermann. The Afrikaners: Biography of a People. Cape Town, Tafelberg, 2003.

The Eastern Frontier, 1770-1812. In: ELPHICK, Richard e GILIOMEE, H. (orgs.) The Shaping of South African Society 16521840. Middletown, Wesleyan University Press, 1979, pp.421-470.

HAMBER, Brandon. Dealing with the Past and the Psychology of Reconciliation. The Truth and Reconciliation Commission, A Psychological Perspective [manuscrito, s/d].

HYSLOP, Jonathan. White Working-class, Women and the Invention of Apartheid: "Purified" Afrikaner Nationalist Agitation for Legislation against "Mixed" Marriages, 1934-1939. Journal of African History, 
"Raça", ressentimento e racismo: transformações na África do Sul

36, 1995, pp.57-81.

KEEGAN, Timothy. White Settlement and Black Subjugation on the South African Highveld: The Tlokoa Heartland in the North Eastern Orange Free State, 1850-1914. In: BEINART, W.; DeliUS, P. e TRAPIDO, S. (orgs.) Putting a Plough into the Ground. Accumulation and Dispossession in Rural South Africa, 1850-1930. Johannesburg, Ravan, 1986, pp.218-258.

KOMETSI, Kgamadi. The Individual, Racism and Transformation: a Psychoanalytical Case. Social Dynamcis, 34 (2), 2008, pp.119-127.

LEGASSICK, Martin. The Frontier Tradition in South African Historiography. In: MARKS, S. e ATMORE, A. (orgs.) Economy and Society in Pre-Industrial South Africa. London, Longman, 1980, pp.44-79.

MBEMBE, Achille. Aesthetics of Superfluity. Public Culture, 16 (3), 2004, pp.373-405.

MORRIS, Alan. Race Relations and Racism in a Racially Diverse Inner City Neighbourhood: A Case Study of Hillbrow, Johannesburg. Journal of Southern African Studies, 25 (4), 1999, pp.667-694.

MoutinHo, Laura. Razão, Cor e Desejo: Uma Análise dos Relacionamentos Afetivo-sexuais Inter-raciais no Brasil e na África do Sul. São Paulo, UNESP, 2004.

NUTTALL, Sarah. Entanglement. Literary and Cultural Reflections on post-apartheid. Johannesburg, University of the Witwatersrand Press, 2009.

. Stylizing the Self: The Y Generation in Rosebank, Johannesburg. Public Culture, 16 (3), 2004, pp.31-452.

PENN, Nigel. The Forgotten Frontier: Colonist and Khoisan on the Cape's Northern Frontier in the Eighteenth Century. Athens, Ohio University Press, 2005.

POSEL, Deborah. The Making of Apartheid, 1948-1961. Oxford, Oxford University Press, 1991.

RAMPHELE, Mamphele. A Bed Called Home. Life in the Migrant Labour Hostels of Cape Town. Cape Town, David Phillip, 1993. 
STEYN, Melissa. Whiteness in the Rainbow: Experiencing the Loss of Privilege in the New South Africa. In: HAMILTON, Charles V.; Huntley, Lynn; AleXANDER, Neville; GuimarãES, Antonio Sérgio Alfredo e JAMES, Wilmot. (orgs.) Beyond Racism: Race and Inequality in Brazil, South Africa and the United States. London, Lynne Rienner, 2001a, pp.85-103.

"Whiteness Just Isn't What it Used to be": White Identity in a Changing South Africa. Albany, State University of New York Press, 2001b.

Van OnSElen, Charles. New Babylon New Nineveh. Everyday Life on the Witwatersrand, 1886-1914. Jeppestown, Jonathan Ball, 2001, pp.165-204.

YMAG. Bachelor/ettes. Issue n 69, April-May 2007, pp.74-75. 